\title{
Chapter 10 \\ Monoclonal Antibodies to CTLA-4 with \\ Focus on Ipilimumab
}

\author{
Grazia Graziani, Lucio Tentori, and Pierluigi Navarra
}

\begin{abstract}
Cytotoxic T lymphocyte-associated antigen 4 (CTLA-4 or CD152) is a negative regulator of $\mathrm{T}$-cell mediated immune responses, which plays a critical role in suppressing autoimmunity and maintaining immune homeostasis. Because of its inhibitory activity on T cells, CTLA-4 has been investigated as a drug target to induce immunostimulation, blocking the interaction with its ligands. The antitumour effects mediated by CTLA-4 blockade have been attributed to a sustained active immune response against cancer cells, due to the release of a brake on T cell activation. Ipilimumab (Yervoy, Bristol-Myers Squibb) is a fully human monoclonal IgG1 $\kappa$ antibody against CTLA-4 approved by FDA and EMA in 2011 for the treatment of advanced (unresectable or metastatic) melanoma, based on the increase of overall survival demonstrated in a phase III clinical trial. Further development of ipilimumab includes its use in other refractory and advanced solid tumours, either as monotherapy or in combination with additional immunostimulating agents or molecularly targeted therapies.
\end{abstract}

Keywords Ipilimumab • Immunotherapy • Cancer

\section{List of Abbreviations}

$\begin{array}{ll}\text { APC } & \text { Antigen-presenting cells } \\ \text { CTLA-4 } & \text { Cytotoxic T-lymphocyte antigen-4 } \\ \text { FoxP3 } & \text { Transcription factor forkhead box protein P3 } \\ \text { HRQL } & \text { Health-related quality of life }\end{array}$

G. Graziani $(\bowtie) \cdot$ L. Tentori

Department of System Medicine, Pharmacology Section, University of Rome "Tor Vergata",

Via Montpellier 1, 00133 Rome, Italy

e-mail: graziani@uniroma2.it

P. Navarra

Institute of Pharmacology, Catholic University Medical School, Rome, Italy 


$\begin{array}{ll}\text { ICOS } & \text { Inducible costimulator } \\ \text { IDO } & \text { Indoleamine 2,3-dioxygenase } \\ \text { irAEs } & \text { Immune-related adverse effects } \\ \text { irRC } & \text { Immune-related criteria } \\ \text { LAT } & \text { Linker for activation of T cells } \\ \text { MHC } & \text { Major histocompatibility complex } \\ \text { mWHO } & \text { Modified World Health Organization } \\ \text { NIBIT } & \text { Italian Network of Tumour Biotherapy } \\ \text { NSCLC } & \text { Non-small-cell lung cancer } \\ \text { PD-1 } & \text { Programmed death-1 } \\ \text { PI3K } & \text { Phosphatidylinositol 3-kinase } \\ \text { PKC } & \text { Protein kinase C } \\ \text { PLC } & \text { Phospholipase C } \\ \text { PP2A } & \text { Serine-threonine protein phosphatase 2A } \\ \text { PSA } & \text { Prostate-specific antigen } \\ \text { RECIST } & \text { Response Evaluation Criteria in Solid Tumours } \\ \text { REMS } & \text { Risk Evaluation and Mitigation Strategy } \\ \text { SCLC } & \text { Small-cell lung cancer } \\ \text { SHP2 } & \text { src homology 2 domain-containing tyrosine phosphatase 2 } \\ \text { TCR } & \text { T-cell receptor } \\ \text { Tregs } & \text { Regulatory T cells }\end{array}$

\section{Contents}

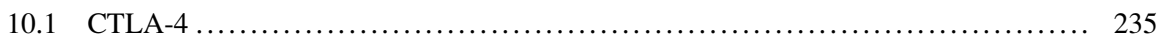

10.2 CTLA-4 as Pharmacological Target for Immunosuppression or Immunostimulation 238

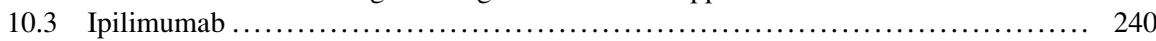

10.3.1 Clinical Efficacy Studies with Ipilimumab ........................ 241

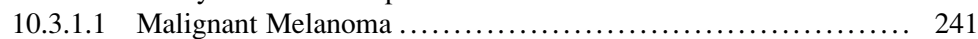

10.3.1.2 Hormone-Sensitive and -Resistant Prostate Cancer ............. 246

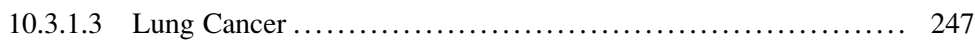

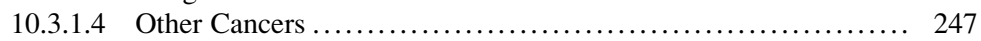

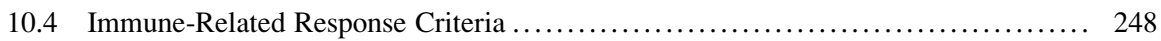

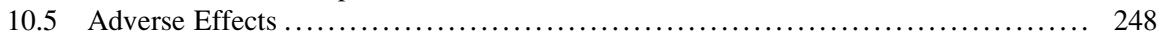

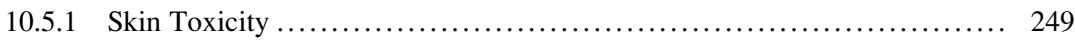

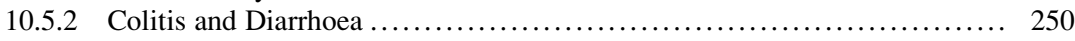

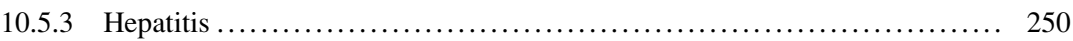

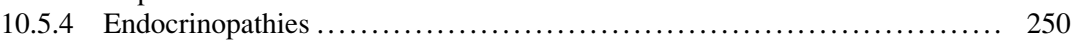

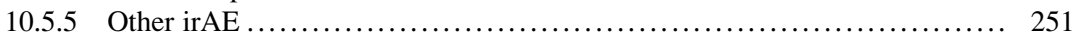

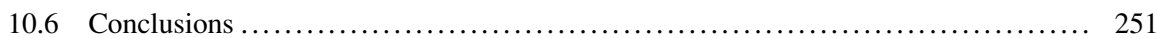

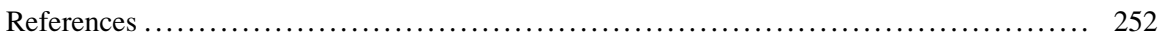




\subsection{CTLA-4}

Cytotoxic T lymphocyte-associated antigen 4 (CTLA-4 or CD152) is a negative regulator of $\mathrm{T}$ cell-mediated immune responses, which plays a critical role in suppressing autoimmunity and maintaining immune homeostasis. The inhibition of the effector T-cell function is induced by CTLA-4 using both effector T-cell "intrinsic" (i.e., transducing a cell-intrinsic negative signal directly in effector T cells) and "extrinsic" mechanisms.

CTLA-4 acts as a negative regulator of CD28-dependent T-cell responses (Fig. 10.1). After the binding of T-cell receptor (TCR) with an antigen bound to the major histocompatibility complex (MHC) on the surface of antigen-presenting cells (APC), T-cell activation is completed by a second co-stimulatory signal, represented by the interaction between $\mathrm{CD} 28$ on $\mathrm{T}$ cells and the $\mathrm{B} 7$ molecules on APC (Fig. 10.1). The main effects of CD28 signalling are to augment and sustain $\mathrm{T}$-cell responses, favour survival of $\mathrm{T}$ cells and direct the production of cytokines required for clonal expansion and differentiation of T cells. CTLA-4 is closely related to $\mathrm{CD} 28$ and shares with it the same ligands, B7-1 (CD80) and B7-2 (CD86), with CTLA-4 exhibiting higher affinities than CD28, in particular for CD80 [1, 2]. Like CD28 and the other costimulatory receptor inducible costimulator (ICOS), CTLA-4 is a transmembrane protein bearing a single extracellular immunoglobulin variable domain linked to a stalk region, containing a unique cysteine residue responsible for the formation of disulfide-linked homodimers, and a transmembrane segment followed by a short cytoplasmic tail endowed with tyrosine-based signalling motifs [3]. Despite their structural and sequence similarities, CD28 and CTLA-4 differ in their localization in T cells, the former being expressed at the cell surface both in resting and activated cells. CTLA-4 is, instead, up-regulated on the surface of activated T cells in response to TCR/CD28 costimulation [3]. In resting T cells, CTLA-4 has a primarily intracellular distribution that is dependent on motifs contained within its $\mathrm{C}$ terminal cytoplasmic tail. Upon T-cell stimulation, CTLA-4 is mobilized to the cell surface but not stabilized at the plasma membrane; in fact, it continues to undergo clathrinmediated endocytosis, recycling, and degradation [4]. Once expressed on plasma membrane of activated T cells, CTLA-4 outcompetes with CD28 for the binding to B7 complex inhibiting T-cell activation, as a result of decreased proliferation and impairment of CD28-mediated interleukin 2 (IL-2) secretion [3]. CTLA-4 inhibits signal-transduction pathways downstream of TCR through the interaction of its cytoplasmic tail with serine-threonine protein phosphatase 2A (PP2A) and src homology 2 domain-containing tyrosine phosphatase 2 (SHP2) [5]. Moreover, it stimulates T-cell survival through the binding of phosphoinositol-3 kinase (PI3K), inducing T-cell anergy in the absence of T-cell death [5]. The CTLA-4 induced PI3K activation generates phosphatidylinositol 3,4-biphosphate (PIP2) which recruits $\mathrm{PH}$ domain kinase 1 (PDK1), a kinase capable of activating serine-threonine protein kinase $\mathrm{B}$ (PKB/AKT). The latter enzyme, in turn, phosphorylates and inactivates the pro-apoptotic protein $\mathrm{BAD}$, which is degraded 


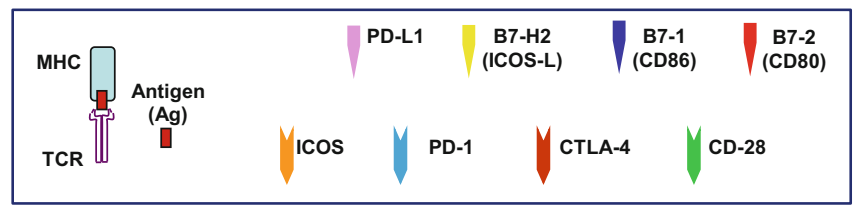

a

\section{COSTIMULATORY AND COINHIBITORY RECEPTORS}

APC

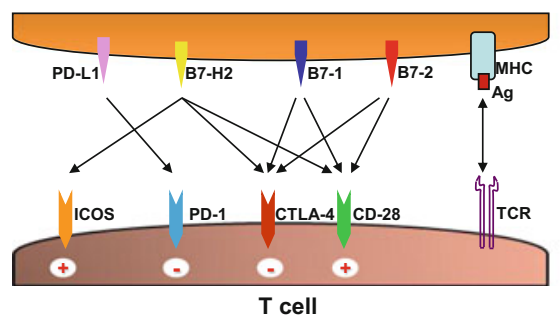

b

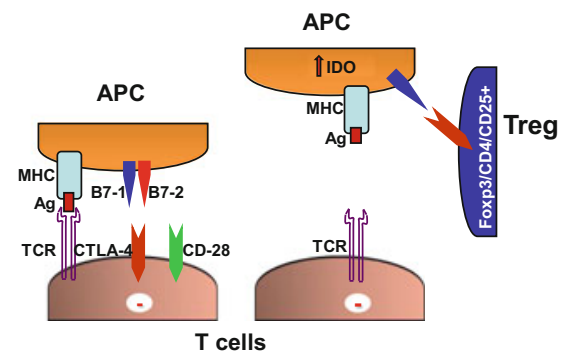

Fig. 10.1 CTLA-4 is a negative modulator of $\mathrm{T}$ cell activation. a Costimulatory and coinhibitory molecules. T-cell activation is triggered when TCR binds to an antigen bound to the MHC on the surface of APC, and it is completed by a second co-stimulatory signal, represented by the interaction between CD28 on T cells and its ligands B7-1 (CD80) or B7-2 (CD86) expressed on APC. PD-1 and CTLA-4 are negative regulators of T-cell-mediated immune responses. CTLA-4 shares with CD28 the same ligands, B7-1 and B7-2. ICOS is a costimulatory receptor and its ligand, B7-H2 (ICOS-L), has recently been proposed to bind also CD28 and CTLA-4. (The plus sign represents a positive/activating signal; the minus sign indicates a negative/inhibitory signal). b Inhibition of T-cell activation. Following T-cell activation, CTLA-4 is up-regulated in activated effector T cells, and functions as an inhibitory co-stimulatory molecule, outcompeting with CD28 for the binding to B7 complex. CTLA-4 is constitutively expressed on Tregs surface, and its interaction with B7 molecules triggers a reverse signalling in APC that leads to up-regulation in APC of IDO, reducing the supply of tryptophan in the local tissue microenvironment and producing kynurenines, with consequent inhibition of T-cell proliferation. Other mechanisms involved in CTLA-4 inhibitory effects on T-cell activation are described in the text

by 14-3-3 proteins, preventing its interaction with the anti-apoptotic Bcl-xL and $\mathrm{Bcl}-2$ proteins, and causes up-regulation of $\mathrm{Bcl}-\mathrm{xL}$ expression. In this way, $\mathrm{Bcl}-\mathrm{xL}$ and Bcl-2 are free to mediate mitochondrial-dependent cell survival [6]. Through this pathway, CTLA-4 favours T-cell survival under condition of anergy induction, thus ensuring the maintenance of a long-term tolerance in the immune system.

Other intrinsic mechanisms by which CTLA-4 inhibits T-cell activation rely on the ability of CTLA-4 to increase T-cell motility, overriding the TCR-mediated "stop-signal" (i.e., the arrest of T-cell motility), which is required for a stable conjugate formation between T cells and APC [7]. In this way, CTLA-4 decreases the contact period between T cells and APC, reduces the efficiency of MHC-peptide presentation, and raises the threshold for T-cell activation conferring protection against autoimmunity. Moreover, CTLA-4 inhibits the expression of lipid rafts, a 
clustering of glycosphingolipid-enriched microdomains that is considered as an essential component of the immunologic synapse [8]. Lipid rafts form, on the T-cell surface, a "platform" for signalling proteins crucial for proper TCR-mediated signalling. After TCR engagement, molecules such as Lck, Fyn, protein kinase C (PKC) $\theta$, phospholipase C (PLC) $\gamma$, and linker for activation of T cells (LAT), are recruited to the raft aggregates at the T cell-APC contact area. During CTLA-4 interaction with the rafts, its associated phosphatases might dephosphorylate important signal components and then cause dissociation of the raft associated molecules such as Lck, Fyn, LAT, and TCR chain [8]. Finally, CTLA-4 also blocks the formation of microclusters containing TCR and molecules needed for an effective transmission of signals from TCR [9].

A well-characterized extrinsic mechanism by which CTLA-4 may act as negative regulator of T-cell responses is through the action of regulatory $\mathrm{T}$ cells (Tregs) (Fig. 10.1), where CTLA-4 is constitutively expressed [10]. Tregs are a subset of TCR $\alpha \beta^{+} \mathrm{CD}^{+} \mathrm{T}$ cells, which behave as immunosuppressive regulators both through the production of cytokines and by direct cell-cell contacts [11]. They are characterized by surface expression of IL-2 receptor alpha chain (CD25) and intracellular expression of the X-chromosome-linked transcription factor forkhead box protein P3 (FoxP3). In Tregs, CTLA-4 expression is controlled by Foxp3 and further up-regulated by TCR stimulation. These Foxp $3^{+} \mathrm{CD} 4^{+} \mathrm{CD} 25^{+}$Tregs suppress naïve T-cell activation (referred to as "suppression"), have impaired TCR signal transduction ("TCR hyposignalling"), scarcely produce IL-2 and are anergic in vitro ("anergy"), although they are highly proliferative when provided with an exocrine source of IL-2 [12]. Recently, it has been found that Treg suppression and anergy require the external domain of CTLA-4, which binds to costimulatory ligands on APCs, whereas TCR hyposignalling only requires CTLA-4 internal domain [12]. Suppression of the activation of naïve T cells associated with Treg externalization of CTLA-4 can be mediated by its interaction with CD80/CD86, which triggers a reverse signalling in APC, causing up-regulation of the indoleamine 2,3-dioxygenase (IDO), an enzyme involved in the catabolism of tryptophan. The increase in IDO activity limits the available tryptophan in the local tissue microenvironment, required for T-cell proliferation, and enhances the formation of kynurenines which induce apoptosis in T cells [13-16]. The tryptophan starvation and the presence of kynurenines can also stimulate the conversion of naïve $\mathrm{CD}^{+} \mathrm{CD} 25^{-} \mathrm{T}$ cells into highly suppressive $\mathrm{CD} 4^{+} \mathrm{CD} 25^{+} \mathrm{FoxP}^{+}$Tregs, further expanding the Treg cell compartment [17].

CTLA-4 proteins have been shown to induce costimulatory blockade either by sequestering or removing costimulatory ligands from the APC surface. In fact, Tregs expressing CTLA-4 on the surface can induce the down-regulation of CD80 and CD86 on APC, limiting the activation of naïve T cells via CD28 [18]. CTLA-4 expressed in Tregs or in activated $\mathrm{T}$ cells is able to capture and remove co-stimulatory ligands (i.e., CD80 and CD86) from opposing cells by transendocytosis. Following removal, these costimulatory ligands are degraded inside CTLA-4-positive cells, depriving T cells of CD28-mediated co-stimulation [19]. 


\subsection{CTLA-4 as Pharmacological Target for Immunosuppression or Immunostimulation}

Because of its inhibitory activity on T-cell-mediated responses, CTLA-4 has been investigated as a drug target either to induce immunosuppression, using agents that mimic its function, or, conversely, to induce immunostimulation, blocking the interactions with its ligands (Fig. 10.2). With regard to immunosuppressive compounds that amply the CTLA-4 function, abatacept and belatacept are recombinant soluble homodimeric fusion proteins composed by the extracellular domain of CTLA-4 fused with the hinge region, and $\mathrm{CH} 2$ and $\mathrm{CH} 3 \mathrm{Fc}$ portions of human IgG1 [20, 21]. Via their CTLA-4 portion, these recombinant proteins act as competitors in the binding of CD28 to CD80/86 with CD28 on T cells, thus inhibiting full T-cell activation (Fig. 10.3). The Fc portion of both recombinant proteins has been deliberately mutated at three sites so that it lost the complement binding and Fc receptor-binding capabilities. For this reason, the Fc portion present in abatacept and belatacept cannot trigger complement-dependent cytotoxicity and antibody-dependent cellular cytotoxicity. Abatacept (Orencia, Bristol-Myers Squibb) was approved in 2006 by FDA and in 2007 by EMA for rheumatoid arthritis and polyarticular juvenile idiopathic arthritis [20]. Belatacept (Nulojix, Bristol-Myers Squibb), which differs from abatacept in two amino acid residues in the CTLA-4 part and binds with greater avidity to CD80/86 compared with abatacept, received approval in 2011 by FDA and EMA to prevent rejection of kidney transplantations [21] (Fig. 10.2).

In contrast, since it is known that tumours have developed numerous ways to suppress and evade the immune system, the blockade of CTLA-4 signalling was expected to prolong T-cell activation and to amplify T-cell-mediated immunity against cancer cells. Preclinical evidence that abrogation of CTLA-4 function would have resulted in increase of T-cell activation and proliferation came from CTLA-4 knock-out mice, which showed a massive CD28-dependent expansion of autoreactive T cells in lymph nodes, spleen, and other peripheral tissues, causing severe myocarditis and death by $3-4$ weeks of age $[22,23]$. In-vivo preclinical studies in the murine model indicated that administration of antibodies to CTLA-4 resulted in the rejection of tumours of different tissue origin, such as colon, prostatic, and renal carcinomas, fibrosarcoma, and lymphoma [24-28].

Two monoclonal antibodies (tremelimumab and ipilimumab) that block the inhibitory signal of CTLA-4 have been developed for clinical use (Fig. 10.2). The antitumour effects mediated by CTLA-4 blockade have been attributed to a sustained active immune response against cancer cells, due to the release of a brake on T-cell activation. The increase of the antitumour immune response appears to derive from a combination of direct enhancement of effector $\mathrm{T}$ cell function and concomitant inhibition of Treg activity through blockade of CTLA-4 on both cell types (Fig. 10.4) [29].

Tremelimumab (CP 675206; CP-675; CP-675,206; CP-675206; ticilimumab; Pfizer) is a fully human non-complement-fixing IgG2 monoclonal antibody. 


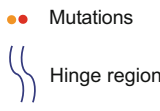

V: Variable

C: Constant

L: Light Chain

H: Heavy Chain

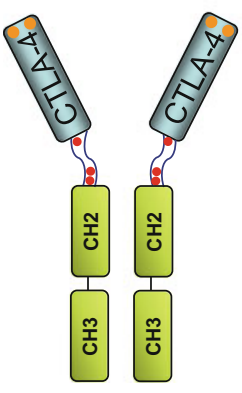

belatacept $\cdots$ abatacept

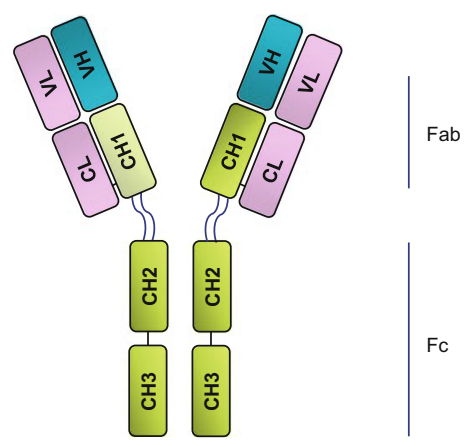

ipilimumab $\lg \mathrm{G} 1$ tremelimumab $\lg \mathrm{G} 2$

Fig. 10.2 CTLA-4 as a target for immunosuppressive or immunostimulating agents. Abatacept was generated by fusing the extracellular domain of human CTLA-4 to the Fc portion of human IgG1. The Fc portion is mutated at three sites (red dots), to eliminate effector functions of the $\mathrm{Fc}$ part. Belatacept was generated by inserting two mutations (orange dots) in the CTLA-4 portion of abatacept to increase the binding avidity to B7-1 and B7-2. Ipilimumab is a fully human monoclonal IgG1 $k$ antibody against the CTLA-4. Tremelimumab is a fully human monoclonal non-complement-fixing IgG2 antibody against CTLA-4
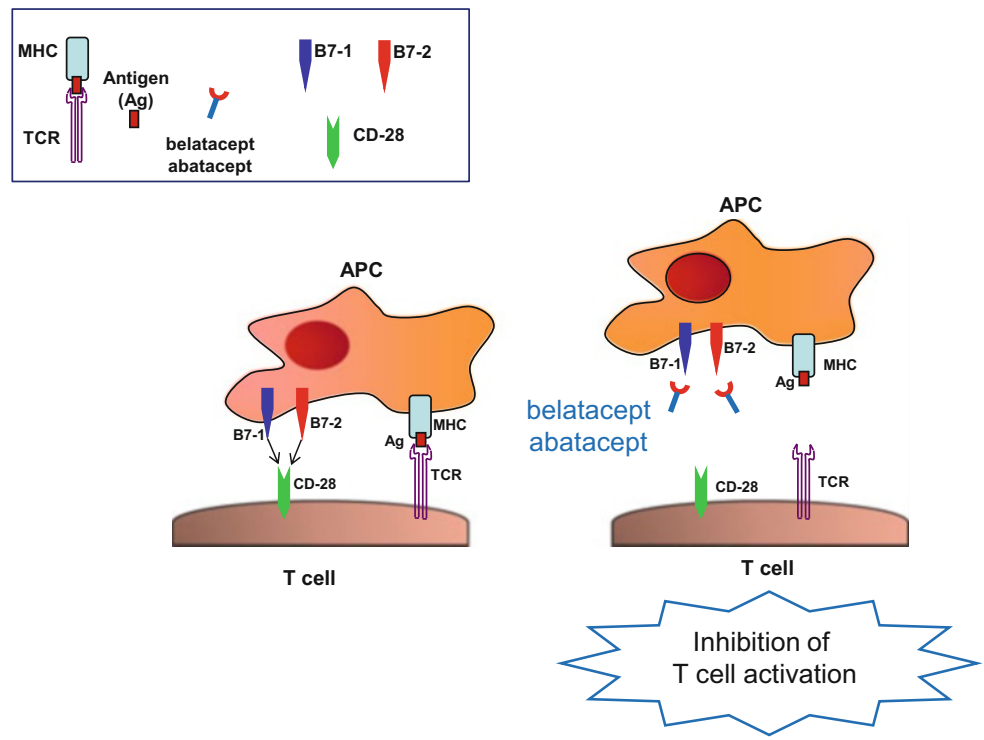

Fig. 10.3 Enhancement of CTLA-4 function. Belatacept or abatacept interfere with CD28/B7 pathway by binding to B7 molecules. Via their CTLA-4 portion, these recombinant proteins prevent the interaction of $\mathrm{B} 7$ with $\mathrm{CD} 28$ on T cells, thus inhibiting full T-cell activation 

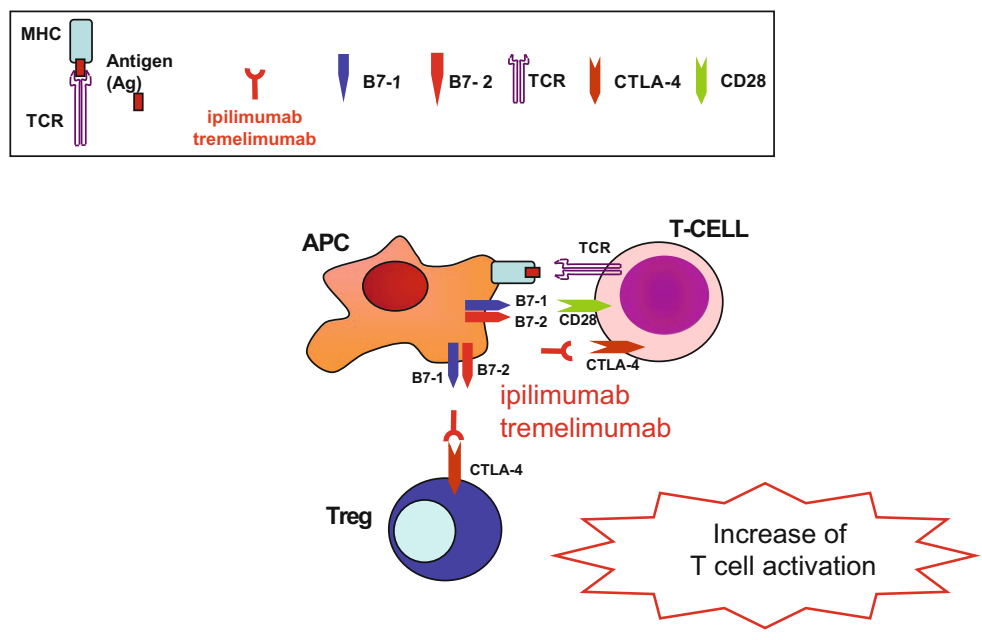

Fig. 10.4 Inhibition of CTLA-4 function. The monoclonal antibodies ipilimab and tremelimumab block CTLA-4 inhibitory signals prolonging T-cell activation and amplifying T-cell-mediated immunity against tumours

Currently, it is in phase I/II clinical trials in combination with short-term androgen deprivation for prostate-specific antigen (PSA)-recurrent prostate cancer without radiographic evidence of metastatic disease, or with the CD40 agonist monoclonal antibody CP-870,893 for metastatic melanoma, and, as single agent, for advanced hepatocellular carcinoma, refractory metastatic colorectal cancer and mesothelioma ([30], http://www.clinicaltrials.gov). In a previous phase III study, tremelimumab monotherapy, as first-line treatment in patients with advanced melanoma, failed to demonstrate an improvement in overall survival with respect to temozolomide or dacarbazine [31]. A recently concluded phase II study, in which 37 patients with metastatic melanoma received tremelimumab in combination with high doses of interferon $\alpha-2 b$, showed that this treatment has an acceptable toxicity profile and promising antitumour efficacy that warrant further testing in randomized trials [32].

The following sections will focus on the pharmacological properties of ipilimumab and on the main results of clinical trials with this agent.

\subsection{Ipilimumab}

Ipilimumab (BMS734016, MDX 101, MDX-010, MDX-CTLA-4, MDX-CTLA4,

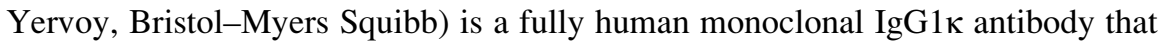
specifically binds to human and cynomolgus CTLA-4. Ipilimumab was originated by the University of Berkeley (CA, USA) and licensed to Medarex, which was then acquired by Bristol-Myers Squibb. The antibody was initially produced by immunizing, with the extracellular domain of CTLA-4, Medarex's proprietary transgenic HuMAb mice (strain $\mathrm{HC} 2 / \mathrm{KCo} 7$ ), which express the human genes 
encoding heavy and light antibody chains and have the corresponding murine genes inactivated. Spleen cells from immunized animals were then fused with a murine myeloma cell line (P3X63Ag8.653) to produce hybridomas, which were screened for IgGk production and CTLA-4 reactivity. The hybridoma 10D1 was selected for further development based on binding specificity, affinity, and ability to block ligand binding [33]. This product was used for phase I studies; for phase II studies and beyond, ipilimumab was produced from a recombinant Chinese hamster ovary (CHO) cell line, transfected with a vector containing the coding sequences for both heavy and light chains of ipilimumab and expressing the same sequence of the antibody produced by the 10D1 hybridoma (EMA/CHMP/557664/2011). The antibody is purified using standard chromatography and filtration steps.

Ipilimumab was approved by FDA in March 2011 for the treatment of unresectable or metastatic melanoma, and in July 2011 by EMA for advanced (unresectable or metastatic) melanoma in adults who have received prior therapy. The recommended dose of ipilimumab is $3 \mathrm{mg} / \mathrm{kg}$ administered intravenously every 3 weeks for a total of four doses.

The pharmacokinetic profile of intravenous ipilimumab was studied in three monotherapy trials on a total of 498 patients with advanced melanoma treated with four doses of $0.3,3$, or $10 \mathrm{mg} / \mathrm{kg}$ every 3 weeks. The values of peak concentration $\left(\mathrm{C}_{\max }\right)$, trough concentration $\left(\mathrm{C}_{\min }\right)$, and area under the curve (AUC) were found to be dose-proportional within the dose range examined. The steady state concentration was reached by the third dose. The $\mathrm{C}_{\max }$ with the $3 \mathrm{mg} / \mathrm{kg}$ approved regimen ranges between $72 \pm 33 \mu \mathrm{g} / \mathrm{ml}$ and $84.5 \mu \mathrm{g} / \mathrm{ml}$, according to different studies [34-37]. Since the maximal blockade of the binding of CD80 and CD86 to human CTLA-4, induced in vitro by ipilimumab, is observed at $6-20 \mu \mathrm{g} / \mathrm{ml}$ and 1-3 $\mu \mathrm{g} / \mathrm{ml}$ respectively, the target $\mathrm{C}_{\min }$ concentration is $20 \mu \mathrm{g} / \mathrm{ml}$. Prior to the second dose of $3 \mathrm{mg} / \mathrm{kg}$ the mean $\mathrm{C}_{\min }$ is $12 \pm 7 \mu \mathrm{g} / \mathrm{ml}$, and the concentration at steady-state is $21.8 \pm 1.2 \mu \mathrm{g} / \mathrm{ml}[36,37]$. The terminal half-life of ipilimumab is 14.7 days $[35,36]$. The mean (percentage coefficient of variation) systemic clearance is $15.3 \mathrm{ml} / \mathrm{h}(38.5 \%)$ and the volume of distribution at steady-state is $7.21 \mathrm{~L}$ $(10.5 \%)$ [36].

\subsubsection{Clinical Efficacy Studies with Ipilimumab}

\subsubsection{Malignant Melanoma}

Melanoma is the most aggressive form of skin cancer that, if detected at an early stage, before dermis invasion, can be cured by surgery in $99 \%$ of patients. In contrast, the median overall survival of patients with metastatic melanoma is low (about 6-9 months), and the expected 2-year survival rate is 10-20\%. The first chemotherapeutic agent approved by FDA in 1975 for the treatment of metastatic melanoma was the DNA methylating compound dacarbazine, which is still considered the reference drug. The response rates with intravenous administration of dacarbazine are 15-25\%, with median response durations of 5-6 months, but 
complete responses are less than $5 \%$. Dacarbazine is unable to cross the blood-brain barrier; thus, it is ineffective against brain metastases that at autopsy can be identified in up to two thirds of patients with metastatic melanoma [38]. The oral dacarbazine analogue temozolomide and the chloroethylating agent fotemustine have also been compared with dacarbazine, but none of these agents were found to be more efficacious $[39,40]$. Temozolomide has been approved by FDA and EMA only for the treatment of newly diagnosed glioblastoma multiforme and recurrent anaplastic astrocytoma. However, it is frequently used off-label for the treatment of metastatic melanoma, especially in the presence of brain metastases, due to its higher brain penetration with respect to dacarbazine. The overall response rates with temozolomide, alone or in combination with whole brain irradiation, in patients with brain metastases from melanoma were up to $9 \%$ [41]. Unfortunately, in a phase III study with 149 patients the global and 1-year incidence of CNS metastases in melanoma patients was not significantly reduced by temozolomide, in combination with cisplatin and IL-2, with respect to the same combination with dacarbazine [42]. A number of studies are currently evaluating temozolomide in combination with other chemotherapeutic agents or with modulators of DNA repair, such as inhibitors of poly(ADP-ribose) polymerase activity ([43], http://www.clinicaltrials. gov). In some European countries, fotemustine is used for the treatment of brain metastases in melanoma patients; the reported overall response rate was $5.9 \%$ versus $0 \%$ with dacarbazine [40]. However, the bone-marrow toxicity induced by fotemustine is more severe than that caused by temozolomide.

In 1998 high doses of IL-2 have been also approved by FDA in USA, but not by EMA in Europe, for the treatment of the metastatic disease, based on the results of phase II studies showing its ability to induce durable responses in 5-7\% of patients [44]. The IL-2 antitumour activity is dependent on its ability to modulate immune responses in the host. The high toxicity (including hypotension, vascular leak syndrome, cardiac dysrhythmias) restricts the use of this cytokine to carefully selected and younger patients with preserved performance status and absence of cardiovascular disease.

The 1-year survival of patients with unresectable melanoma treated with a variety of chemotherapeutic protocols is about $25 \%$, as indicated by the metaanalysis of a large number of phase II trials [45]. Before the recent approval of ipilimumab and of the BRAF inhibitor vemurafenib, no other agents have demonstrated better results than dacarbazine in phase III studies. Vemurafenib (Zelboraf, Hoffman-La Roche) was approved by FDA in August 2011 and by EMA in February 2012 for unresectable or metastatic melanoma with the BRAF V600E mutation as detected by an FDA-approved test. BRAF is a threonine/serine protein kinase that activates the mitogen activation protein (MAP) kinase-ERK pathways. Mutations of BRAF (resulting in about $90 \%$ of cases in glutamic acid substitution for valine at amino acid 600, BRAF V600E) are present in $50 \%$ of melanoma patients, and cause an over-activation of the downstream MAP kinase/ ERK pathway, involved in cell proliferation and survival. Vemurafenib is a smallmolecule kinase inhibitor that selectively targets activated BRAF V600E and lacks activity against melanoma cell lines with wild-type BRAF. Differently from ipilimumab, which is given intravenously for a total of four doses, treatment with 
vemurafenib requires continuous daily doses per os. In a phase III trial enrolling untreated patients with metastatic melanoma carrying the BRAF V600E mutation, the overall survival at 6 months was $84 \%$ in the vemurafenib arm and $64 \%$ in the group treated with dacarbazine, and the response rates were $48 \%$ and $5 \%$ respectively [46]. In previously treated patients with BRAF V600E-mutant metastatic melanoma, vemurafenib induced clinical responses in more than half of patients, with a median overall survival of 16 months [47]. The most commonly reported adverse effects of vemurafenib include arthralgia, rash, photosensitivity, fatigue, pruritus, alopecia, diarrhoea, nausea, and cutaneous squamous-cell carcinoma [46, 47]. Evidence on the clinical efficacy deriving from targeting BRAF V600E also derives from the results of a phase III trial with the other BRAF inhibitor dabrafenib that led to drug approval in 2013 (GSK-2118436, GlaxoSmithKline) [48]. Unfortunately, responses to BRAF inhibitors are short-lived due to the development of different mechanisms of acquired tumour drug resistance that lead to the recovery of the MAPK signalling. Among these resistance mechanisms, switching between BRAF isoforms or secondary activating NRAS mutations are frequently described [49]. Interestingly, the cutaneous squamous-cell carcinomas and keratoacanthomas that develop in $15-30 \%$ of patients treated with vemurafenib or dabrafenib frequently show RAS mutations [50].

The approval of ipilimumab by FDA was based on its ability to increase the overall survival with respect to vaccine with gp100 peptide in a phase III study (NCT00094653/CA184-002) that recruited 676 patients with unresectable stage III or IV melanoma, whose disease had progressed after at least one prior systemic treatment with chemotherapy [51]. This phase III study is the first randomized clinical trial showing increased overall survival in patients with metastatic melanoma (about $70 \%$ of the patients had visceral metastases), and the first reporting efficacy as second-line treatment of melanoma. The patients were randomly in a $3: 1: 1$ fashion to receive: ipilimumab $(3 \mathrm{mg} / \mathrm{kg})$ plus gp100 (1 mg each of two modified peptides) every 3 weeks for four doses, ipilimumab plus placebo, and gp100 plus placebo. All patients were HLA-A*0201-positive, since the cancer vaccine consists of a nine amino acid synthetic peptide derived from the melanosomal glycoprotein 100 (gp100) that is presented to the immune system in the context of HLA-A*0201. Before ipilimumab approval, no accepted standard of care for second-line therapy of metastatic melanoma was available, and enrolment in a clinical trial was recommended. The median overall survival with ipilimumab alone was 10.1 months, while with gp100 alone it was 6.4 months. The rationale of evaluating ipilimumab in combination with gp100 was based on the hypothesis that the addition of the cancer vaccine might have enhanced $\mathrm{T}$-cell responses compared with ipilimumab alone. However, ipilimumab did not synergize with the vaccine, since the overall survival of the combined treatment was identical to that of ipilimumab alone [51]. On the other hand, gp100 was recently found to increase the efficacy of IL-2 in patients with locally advanced stage III or IV melanoma [52].

Ipilimumab, as single agent or in combination with gp100, almost doubled the 1or 2-year survival rate for patients with stage III or IV melanoma. In fact, the rates of overall survival in the ipilimumab plus gp100 group, the ipilimumab-alone group 
and the gp100-alone group, respectively, were $43.6 \%, 45.6 \%$, and $25.3 \%$ at 1 year, and $21.6 \%, 23.5 \%$, and $13.7 \%$ at 2 years [51]. A retrospective analysis of pooled efficacy data stratified by HLA-A*0201 status showed that ipilimumab-treated patients had similar outcomes regardless of their HLA-A*0201 status [53]. Despite the fact that the NCT00094653 study was done exclusively in patients who had failed prior therapy, FDA approved ipilimumab, at the dose of $3 \mathrm{mg} / \mathrm{kg}$, for all patients affected by metastatic melanoma, both those who were treatment-naïve and those who had failed previous therapy. Approval almost coincided with the announcement by Bristol-Myers Squibb Company that a phase III study (NCT00324155/CA184-024) in 502 previously untreated patients, comparing the efficacy of $10 \mathrm{mg} / \mathrm{kg}$ ipilimumab plus dacarbazine versus monotherapy with dacarbazine, had met the primary endpoint of improving overall survival. The results, published 3 months later, indicated that ipilimumab every 3 weeks for four doses in combination with dacarbazine $\left(850 \mathrm{mg} / \mathrm{m}^{2}\right)$ significantly improved overall survival compared to dacarbazine plus placebo (11.2 months versus 9.1 months) as the front-line metastatic setting [54]. After the induction phase, eligible patients received a maintenance therapy with ipilimumab every 12 weeks. The survival rates in the ipilimumab-dacarbazine arm were higher than in the dacarbazine arm, being $47.3 \%$ and $36.3 \%$ at 1 year, $28.5 \%$ and $17.9 \%$ at 2 years respectively. In the ipilimumab-dacarbazine group, prolonged survival was observed in patients monitored for 4 years [54]. A randomized double-blind phase III study (NCT01515189/CA184-169) is presently comparing $3 \mathrm{mg} / \mathrm{kg}$ with $10 \mathrm{mg} / \mathrm{kg}$ ipilimumab in patients with previously treated or untreated unresectable or metastatic melanoma. Moreover, a phase II study (NCT01119508/2009-0408) is evaluating the efficacy and safety of $10 \mathrm{mg} / \mathrm{kg}$ ipilimumab in combination with temozolomide $\left(200 \mathrm{mg} / \mathrm{m}^{2}\right)$ on day $1-4$, every 3 weeks for four courses, followed by a maintenance therapy with ipilimumab every 12 weeks and temozolomide on day 1-5 every 4 weeks until the occurrence of disease progression or unacceptable toxicity. The results on 64 patients indicated that the treatment was well-tolerated and efficacious in this clinical setting [55]. Moreover, a prospective phase I/II doseescalation trial is investigating the safety of the combination of ipilimumab plus vemurafenib in patients with metastatic melanoma containing the BRAF V600E mutation (NCT01400451/CA184-161) [56].

Apart from the phase III registration trial used by FDA for ipilimumab approval (NCT00094653/CA184-002) in which 10-15\% of patients in each arm presented CNS involvement at baseline [51], in most of the clinical trials with ipilimumab, patients with brain metastases were excluded. The outcomes among these patients are quite poor; in fact, after diagnosis of brain metastases the median overall survival is only 4 months [57]. Previous case reports showed clinical benefits of ipilimumab for brain metastases from melanoma [58, 59]. Moreover, a recent phase II trial specifically designed to enrol patients with brain metastases (NCT00623766/ CA184-042) indicated that $10 \mathrm{mg} / \mathrm{kg}$ ipilimumab has activity in this clinical setting, particularly when metastases are stable, asymptomatic, and do not need glucocorticosteroid treatment [60]. Moreover, the Italian Network of Tumour Biotherapy (NIBIT) has evaluated the efficacy of ipilimumab $(10 \mathrm{mg} / \mathrm{kg}$ every 3 weeks for four 
doses and once every 12 weeks from week 24) in combination with fotemustine $\left(100 \mathrm{mg} / \mathrm{m}^{2}\right.$ weekly for 3 weeks and every 3 weeks from week 9$)$ in a phase II study (NIBIT-M1) for patients with metastatic melanoma, with or without brain metastases [61-63]. Of the 86 patients enrolled in this study, 20 showed brain metastases, and combination of ipilimumab with fotemustine was found to be active regardless of prior treatment, warranting further investigation in a subsequent phase III NIBIT-M2 trial [62].

Conventional treatment options for melanoma brain metastases consist of surgical resection, whole-brain radiation and stereotactic radiotherapy. An effect observed when ipilimumab was combined with radiotherapy is the abscopal effect, a phenomenon related to activation of the immune system, in which local radiotherapy is associated with the regression of metastatic cancer at a distance from the irradiated site. The regression of non-irradiated lesions in melanoma patients treated with radiotherapy and ipilimumab suggests a potential synergism between these two therapeutic approaches [64, 65]. Indeed, several phase I/II clinical trials are evaluating the combination of ipilimumab with radiation therapy for the treatment of unresectable stage III or stage IV melanoma (http://www.clinicaltrials.gov). According to the experiences of the Italian Medical Oncology and Immunotherapy Unit at the University Hospital of Siena, in the context of an ipilimumab-ocular melanoma expanded access program, and of the Memorial Sloan Kettering cancer centre, ipilimumab monotherapy has shown promising activity also for uveal melanoma [66, 67]. Trials are currently recruiting patients for this clinical setting [NCT01585194/2011-0919, NCT01355120/DeCOG-MM-PAL11].

Ipilimumab is also being tested in phase III trials as adjuvant therapy after surgical removal of melanoma for patients with high-risk stage III or IV, versus high-dose interferon $\alpha$-2b (NCT01274338/ECOG-E1609) or versus placebo (NCT00636168/CA184-029). A neoadjuvant use of ipilimumab monotherapy (NCT00972933/08-144) or in combination with high doses of interferon $\alpha-2 b$ (NCT01608594/NCT01608594) is currently under evaluation in patients with stage IIIB/C melanoma before surgery. These studies also aim at comparing immunological parameters at baseline and after treatment. Data on 30 patients indicated that ipilimumab induced a significant increase in the frequency of circulating Tregs at 6 weeks, and that greater increases in Tregs were associated with improved progression-free survival [68].

Phase II combination studies are currently testing ipilimumab with other immunostimulating agents, such as nivolumab (BMS-936558), a fully human monoclonal antibody against programmed death-1 (PD-1), an inhibitory receptor expressed on activated T cells (NCT01927419/CA209-069), or various cancer vaccine. One of the vaccines combined with ipilimumab is TriMix-DC, formed by of autologous dendritic cells, transfected with mRNA encoding CD40 ligand, constitutively active toll-like receptor 4 , and CD70. The dendritic cells have been further co-electroporated with mRNA encoding the melanoma-associated antigens MAGE-A3, MAGE-C2, tyrosinase, and gp100 [69], in order to induce a T-cell repertoire able to recognize in a HLA-restricted way these melanoma antigens (NCT01302496/2010-023058-35). 


\subsubsection{Hormone-Sensitive and -Resistant Prostate Cancer}

The standard of care for hormone-sensitive metastatic prostate cancer is androgen deprivation therapy via medical [i.e., with the gonadotropin-releasing hormone $(\mathrm{GnRH})$ agonist/analogues leuprolide or goserelin or with the $\mathrm{GnRH}$ antagonist degarelix] or surgical castration. However, most recurrent prostate cancers that initially responded to androgen deprivation therapy eventually become castrationresistant. Once the prostate cancer becomes refractory to hormonal therapy, the disease course is uniformly fatal, since the treatment options available so far only modestly extend survival. Docetaxel-based regimens are regarded as the standard first-line chemotherapy for metastatic castration-resistant prostate cancer. Recently, cabazitaxel, a semisynthetic taxane derivative, and abiraterone, a pregnenolone derivative that irreversibly inhibits CYP17A (a key enzyme in androgen synthesis), have been approved for patients previously treated with a docetaxel-containing regimen. In addition, immunotherapy with sipuleucel-T, an autologous antigenpresenting cell vaccine loaded with prostate acid phosphatase conjugated with granulocyte-macrophage colony-stimulating factor (GM-CSF), was approved for men with asymptomatic metastatic disease [70]. Ipilimumab has shown some activity in several phase I/II clinical trials in metastatic prostate cancer, as single agent [71] and in combination with GM-CSF [72] or radiotherapy [73]. A phase II study with ipilimumab given alone or in combination with docetaxel has been recently completed (NCT00050596/CA184-019). Two multicentre randomized phase III studies, both with overall survival as primary endpoint, are currently underway in chemotherapy-naïve or post-docetaxel patients with metastatic castration-resistant prostate cancer. One of these studies is comparing radiotherapy followed by ipilimumab $(10 \mathrm{mg} / \mathrm{kg})$ versus radiotherapy plus placebo in patients who have received prior treatment with docetaxel (NCT00861614/CA184-043) [74], based on data supporting a role for irradiation to enhance the immune responses, whereas the other is testing the same dose of ipilimumab versus placebo in asymptomatic or minimally symptomatic chemotherapy-naïve patients (NCT01057810/CA184-095) [75].

Phase II studies with ipilimumab in combination with either GnRH analogues (leuprolide, goserelin) or the GnRH antagonists degarelix plus androgen deprivation therapy in castrate-sensitive prostate carcinoma (NCT01377389/2009-0378), or as neoadjuvant therapy before surgery (NCT01194271/2009-0135), are ongoing.

Based on the previously reported synergy between the anti-CTLA-4 antibody in combination with GM-CSF secreting tumour-cell vaccines, a phase I trial with GMCF-transduced allogeneic prostate cancer cells vaccine (GVAX) plus $3 \mathrm{mg} / \mathrm{kg}$ ipilimumab has been undertaken in patients with metastatic castration-resistant prostate cancer (NCT01510288/G-0016) [76]. Moreover, another phase I study (NCT00113984/NCT00124670) has been carried out with escalating doses of ipilimumab plus PSA-Tricom vaccine, a poxviral-based vaccine targeting PSA and containing three T-cell co-stimulatory molecules (CD58, CD80, and ICAM1) [77]. 


\subsubsection{Lung Cancer}

About 85-90\% of all lung cancers are non-small-cell lung cancers (NSCLC); at an advanced stage, standard chemotherapy only marginally improves overall survival. Platinum-based combination therapies are the standard of first-line care for patients with advanced NSCLC, with a median overall survival of 8-12 months. In 203 chemotherapy-naïve recurrent or stage IIIb/IV patients with NSCLC, $10 \mathrm{mg} / \mathrm{kg}$ ipilimumab was administered concomitantly with (concurrent ipilimumab) or sequentially (phased ipilimumab) to carboplatin and paclitaxel, and compared to chemotherapy alone (NCT00527735/CA184-041). The results of this phase II trial indicated that phased ipilimumab plus paclitaxel and carboplatin improved progression-free survival (phased ipilimumab 5.1 months and concurrent ipilimumab 4.1 months versus chemotherapy alone 4.2 months). Median overall survival were 12.2, 9.7, and 8.3 months respectively [78]. A phase III trial has been recently planned to test the impact of paclitaxel/carboplatin followed by ipilimumab on overall survival in NCSLC with squamous histology (NCT01285609/CA184-104) [79]. Similar results to those obtained with NCSLC were reported also in patients with extensive-disease small-cell lung cancer (ED-SCLC) who were enrolled onto the same phase II study NCT00527735/ CA184-041 [78]. For newly diagnosed ED-SCLC, a phase III trial (NCT01450761/CA184-156) is recruiting patients to compare the efficacy of ipilimumab plus etoposide/cisplatin or carboplatin, which represent the standard treatment for metastatic SCLC [80].

\subsubsection{Other Cancers}

Ipilimumab is in phase I/II clinical trials for a variety of solid tumours. In renal cell cancer, immunotherapy with IL-2 induces $15-25 \%$ objective response rate. In a phase II trial (NCT00057889/NCI-03-C-0094) with 61 patients affected by metastatic renal cell cancer, refractory to or ineligible for treatment with IL-2 treatment, single-agent ipilimumab $(1 \mathrm{mg} / \mathrm{kg}$ and $3 \mathrm{mg} / \mathrm{kg})$ induced an overall response rate of $12.5 \%$ in the group receiving the higher dose of ipilimumab, and responses were seen in patients previously not responding to IL-2 [81]. Another phase II study (NCT01524991/GU10-148) has been designed to assess the efficacy of ipilimumab in combination with gemcitabine and cisplatin against metastatic urothelial carcinoma, which is regarded as an immunogenic tumour and is generally treated with first-line platinum-based combinations [82]. A small phase I study has also evaluated the tolerability of ipilimumab as neoadjuvant treatment for urothelial carcinoma before surgery (NCT00362713/CA184-027) [83]. Phase I trials are testing the safety of ipilimumab in combination with gemcitabine (NCT01473940/NU 10I02) or with a pancreatic cancer vaccine, consisting of allogeneic pancreatic tumour cells transfected with a GM-CSF gene (NCT00836407/J0834), for locally advanced, unresectable, or metastatic pancreatic adenocarcinoma. 


\subsection{Immune-Related Response Criteria}

The clinical experience with ipilimumab has indicated that the Response Evaluation Criteria in Solid Tumours (RECIST) or modified World Health Organization (mWHO) criteria, typically used by oncologists to define tumour response and disease progression, are not suitable for assessing the clinical responses to imuunotherapy. In fact, patients treated with ipilimumab may have a delayed yet durable response and obtain long-term survival benefit despite an initial tumour growth. On the contrary, the cytotoxic activity of chemotherapeutic agents generally causes tumour shrinkage within a few weeks from the beginning of drug administration. A decrease in tumour size after the initial cycle of chemotherapy is predictive of improved survival, whereas an early increase of the primary tumour or the appearance of new lesions is indicative of progressive disease and drug failure. On the other hand, ipilimumab, due to its particular mechanism of action that relies on activation of $\mathrm{T}$-cell mediated immune responses against the tumour, may induce four distinct response patterns, all of them associated with a favourable survival: (a) a shrinkage in baseline lesions, (b) a stable disease followed by a slow decline in tumour burden, (c) a response after an increase of tumour burden, or (d) a response in the presence of new lesions [84]. The progression during treatment might indicate an actual tumour growth occurring before an adequate immune response is raised against cancer cells. Alternatively, the progression may reflect an active immune response with infiltration of cytotoxic $\mathrm{T}$ lymphocytes and inflammatory cells within the tumour, which will cause an increase in the size of the lesion [85]. Therefore, RECIST or mWHO criteria might underestimate the clinical benefit of ipilimumab, since an increase in tumour size or the appearance of new lesions would be considered progressive disease, leading to an unwanted early cessation of treatment in potential responders.

This unusual pattern of treatment responses has led to the development of new immune-related criteria (irRC) that may help in the decision-making regarding continuation of therapy [84]. Patients with new lesions, but with a decrease in size of baseline lesions, will not necessarily be considered to have progressive disease. They will, instead, be considered responders and continue to receive ipilimumab, with possible long-term benefits. Nevertheless, the value of irRC has to be tested in prospective clinical trials.

\subsection{Adverse Effects}

The adverse effects of ipilimumab are related to increased immune-reactivity against normal tissues (immune-related adverse effects or irAEs). The most common irAEs include rash and pruritus, colitis and diarrhoea, vitiligo, endocrinopathies involving pituitary, thyroid, or adrenal gland, hepatitis, and uveitis. Indeed, the prescribing information of ipilimumab includes a boxed warning about the risk of severe and fatal irAEs due to T-cell activation and proliferation [36]. Moreover, the 
FDA required a Risk Evaluation and Mitigation Strategy (REMS) from the manufacturer to ensure that the benefits of ipilimumab outweigh its risks. The REMS program consists in a communication plan for healthcare providers and patients to facilitate early identification of the risks deriving from treatment with ipilimumab, and to provide an overview of recommended management of patients with moderate or severe irAEs (http://www.yervoy.com/hcp/rems.aspx).

A retrospective review of safety data from 14 completed phase I-III trials of ipilimumab in 1,498 patients with advanced melanoma indicated that irAEs occurred in $64.2 \%$ of patients, and confirmed that the gastro-intestinal tract and the skin were the most common sites of adverse effects [86]. In the registration phase III trial (NCT00094653/CA184-002), the most common irAE was diarrhoea at any grade in $27-31 \%$ of the patients receiving ipilimumab [51]. Interestingly, health-related quality of life (HRQL) outcomes demonstrated that ipilimumab with/ without gp100 vaccine did not have a significant negative HRQL impact during the treatment induction phase relative to gp100 alone in melanoma patient [87]. Analysis of the safety profile of patients alive after 2 years of the phase III trial NCT00324155/CA184-024, in which ipilimumab plus dacarbazine was compared to dacarbazine plus placebo, indicated a low rate of irAE in the ipilimumabcontaining arm, and indicated that irAE were medically manageable according to established guidelines [88]. Indeed, algorithms are available for the correct management of irAEs, which depends on the severity of adverse effects [89]. Frequencies of dose-limiting ipilimumab-related irAEs increased with dose. Grade 3 and 4 irAE have been reported in $25 \%$ of patients treated with $10 \mathrm{mg} / \mathrm{kg}$, and in $7 \%$ of those treated with $3 \mathrm{mg} / \mathrm{kg}$ [34]. The majority of irAEs resolve with systemic administration of glucocorticosteroids; for grade $\geq 2$ irAEs or in patients experiencing symptomatic endocrinopathy, ipilimumab should be held. Once sideeffects improve to grade $0-1$, steroids should be gradually tapered within at least 1 month. The influence of high-dose systemic glucocorticosteroids on ipilimumab antitumour efficacy has not been established in large-scale trials. Retrospective studies or case reports did not show so far unfavourable effects of steroid treatments on the antitumour efficacy of ipilimumab [90-92]. Several trials have reported a possible correlation between grade 3 and 4 irAEs with the clinical efficacy of ipilimumab [93, 94], suggesting that tumour regression is associated with the development of autoimmunity. However, clinical benefit has been observed also in patients who did not develop irAEs [94].

\subsubsection{Skin Toxicity}

Maculopapular rash and pruritus have been observed in 47-68\% of patients receiving ipilimumab, generally appearing 3-4 weeks after the beginning of treatment. Histological analysis of affected skin revealed perivascular lymphocytic infiltrate in the dermis and epidermis and immunohistochemical staining showed the presence of $\mathrm{CD}^{+}$and melan-A specific $\mathrm{CD}^{+} \mathrm{T}$ lymphocytes in the proximity of apoptotic melanocytes [95]. Skin eruptions and pruritus usually do not require 
skipping a dose or discontinuation of ipilimumab, and resolve with topical glucocorticosteroids or urea-containing creams and antipruritic agents.

\subsubsection{Colitis and Diarrhoea}

Diarrhoea has been observed in $31-46 \%$ of patients, after about 7 weeks, and can be associated with colitis, which can lead to obstruction and bowel perforation $(<1 \%)$. In ipilimumab-related colitis, the descending colon is more often affected than ascending colon, sigmoid colon, or rectum. Colon biopsies show neutrophilic infiltrate in $46 \%$ of patients, lymphocytic infiltrate in $15 \%$, and neutrophiliclymphocytic infiltrate in $38 \%$ [96]. Treatment of mild diarrhoea is symptomatic, with loperamide, oral hydration, and electrolyte substitution. For persistent or grade $\geq 2$ diarrhoea, infection must be excluded by stool cultures, and sigmoidoscopy or colonoscopy is indicated to confirm or rule out colitis [97]. Ipilimumab must be suspended, and budesonide, a locally acting glucocorticosteroid with low bioavailability after oral administration, or $1 \mathrm{mg} / \mathrm{kg}$ prednisone are used. Unfortunately, the prophylactic use of budesonide did not reduce the rate of grade $\geq 2$ gastro-intestinal irAEs [98]. In patients with severe diarrhoea or colitis (grade $\geq 3$ ), ipilimumab should be permanently discontinued. These patients require high-dose intravenous steroids (e.g., methylprednisolone or dexamethasone) or, in case of no improvement after a week, infliximab. Refractory or severe cases of colitis may require ileostomy or colectomy.

\subsubsection{Hepatitis}

Hepatotoxicity (3-9 \%; after 6-7 weeks) is usually revealed by an asymptomatic increase in transaminases and bilirubin or by an immune-mediated hepatitis. Disease progression with metastases in the liver, as well as viral hepatitis must be ruled out. The histologic changes observed with ipilimumab-related hepatitis are similar to those with acute viral and autoimmune hepatitis [99]. For grade 3 and 4 liver toxicity, ipilimumab should be discontinued, and high doses of intravenous glucocorticosteroids given, followed by an oral steroid taper with dexamethasone. If serum transaminase levels do not decrease within $48 \mathrm{~h}$ after the beginning of systemic steroids, oral mycophenolate may be required [97].

\subsubsection{Endocrinopathies}

Among the endocrine dysfunctions provoked by ipilimumab (4-6\%, after about 9-11 weeks), hypophysitis is the most frequently reported. The presenting clinical symptoms relate to a pituitary mass effect and hormonal deficiencies. The enlargement of pituitary gland causes symptoms which mimic intracranial hypertension caused by brain metastases, which need to be excluded. Most patients present with 
headache, fatigue, asthenia, lethargy, nausea, vertigo, behaviour change, loss of libido, or visual disturbances. Typically, low levels of thyroid, adrenal, and gonadal hormones may be found, and clinical symptoms depend on the prevalent suppression of endocrine axes (thyroid, adrenal glands, or gonads). The majority of male patients (83-87\%) have hypogonadotrophic hypogonadism [100]. Treatment of endocrine irAEs includes high-dose steroid therapy and appropriate hormone replacement, which should be undertaken in consultation with an endocrinologist $[89,97]$. Unlike most of the other irAEs, hypophysitis takes a long time to resolve and in many cases persists, requiring lifelong therapy.

\subsubsection{Other irAE}

Immune-related pancreatitis has been reported in less than $1.5 \%$ of treated patients, and generally manifested as an asymptomatic increase of amylase and lipase [93]. Diffuse lymphadenopathy and a sarcoid-like syndrome have been reported anecdotally [101-103]. Transient peripheral neuropathies, both sensory and motor, associated with ipilimumab have been noted in less than $1 \%$ of patients [97]. A case of acquired hemophilia A was diagnosed in a patient with metastatic melanoma 2 months after the introduction of ipilimumab, and was related to ipilimumab therapy [104].

\subsection{Conclusions}

About one third of melanoma patients achieve clinical benefit from ipilimumab treatment, and some of the responses are long-lasting, with follow-up $>5$ years for the earliest studies. The most impressive property of ipilimumab is represented by the ability of a short-course treatment (four doses) to increase the overall survival in a subset of heavily pre-treated patients with metastatic melanoma [51].

The immune-related toxicity of ipilimumab needs a prompt diagnosis and treatment according to product-specific guidelines to adequately manage irAE, which sometimes can be also life-threatening. The use of a specified treatment algorithm has substantially reduced the drug-related deaths to $<1 \%$ of patients, and requires an accurate training of physicians who will use this agent.

The clinical experience with ipilimumab indicates that patients receiving ipilimumab should not have treatment terminated prematurely (unless severe toxicity occurs) because of early progressive disease. In fact, lack of objective response evaluated by standard criteria might not always reflect treatment failure, due to the peculiar kinetics of response deriving from the immune-mediated mechanism of action of ipilimumab. This highlights the importance of identifying biomarkers capable of recognizing those patients who will behave as late responders, in order to spare non-responder patients unnecessary toxicity.

Despite the dramatic effects in a subgroup of patients, the majority of patients with metastatic melanoma do not obtain long-lasting clinical benefit from ipilimumab. 
Thus, combination therapies with other novel immunomodulating agents, targeted therapies, or anti-angiogenic agents need to be evaluated principally to enhance the percentage of long-term survivors, and to improve ipilimumab efficacy.

\section{References}

1. Teft WA, Kirchhof MG, Madrenas J (2006) A molecular perspective of CTLA-4 function. Annu Rev Immunol 24:65-97

2. Chattopadhyay K, Lazar-Molnar E, Yan Q, Rubinstein R, Zhan C, Vigdorovich V, Ramagopal UA, Bonanno J, Nathenson SG, Almo SC (2009) Sequence, structure, function, immunity: structural genomics of costimulation. Immunol Rev 229:356-386

3. Fife BT, Bluestone JA (2008) Control of peripheral T-cell tolerance and autoimmunity via the CTLA-4 and PD-1 pathways. Immunol Rev 224:166-182

4. Qureshi OS, Kaur S, Hou TZ, Jeffery LE, Poulter NS, Briggs Z, Kenefeck R, Willox AK, Royle SJ, Rappoport JZ, Sansom DM (2012) Constitutive clathrin-mediated endocytosis of CTLA-4 persists during T cell activation. J Biol Chem 287:9429-9440

5. Rudd CE, Taylor A, Schneider H (2009) CD28 and CTLA-4 coreceptor expression and signal transduction. Immunol Rev 229:12-26

6. Schneider H, Valk E, Leung R, Rudd CE (2008) CTLA-4 activation of phosphatidylinositol 3-kinase (PI 3-K) and protein kinase B (PKB/AKT) sustains T-cell anergy without cell death. PLoS One 3:e3842

7. Schneider H, Downey J, Smith A, Zinselmeyer BH, Rush C, Brewer JM, Wei B, Hogg N, Garside P, Rudd CE (2006) Reversal of the TCR stop signal by CTLA-4. Science 313: 1972-1975

8. Chikuma S, Imboden JB, Bluestone JA (2003) Negative regulation of T cell receptor-lipid raft interaction by cytotoxic T lymphocyte-associated antigen 4. J Exp Med 197:129-135

9. Schneider H, Smith X, Liu H, Bismuth G, Rudd CE (2008) CTLA-4 disrupts ZAP70 microcluster formation with reduced $\mathrm{T}$ cell/APC dwell times and calcium mobilization. Eur J Immunol 38:40-47

10. Takahashi T, Tagami T, Yamazaki S, Uede T, Shimizu J, Sakaguchi N, Mak TW, Sakaguchi S (2000) Immunologic self-tolerance maintained by CD25(+)CD4(+) regulatory T cells constitutively expressing cytotoxic T lymphocyte-associated antigen 4. J Exp Med 192:303-310

11. Sakaguchi S (2011) Regulatory T cells: history and perspective. Methods Mol Biol 707:3-17

12. Tai X, Van Laethem F, Pobezinsky L, Guinter T, Sharrow SO, Adams A, Granger L, Kruhlak M, Lindsten T, Thompson CB, Feigenbaum L, Singer A (2012) Basis of CTLA-4 function in regulatory and conventional CD4+ T cells. Blood 119:5155-5163

13. Grohmann U, Orabona C, Fallarino F, Vacca C, Calcinaro F, Falorni A, Candeloro P, Belladonna ML, Bianchi R, Fioretti MC, Puccetti P (2002) CTLA-4-Ig regulates tryptophan catabolism in vivo. Nat Immunol 3:1097-1101

14. Mellor AL, Munn DH (2004) IDO expression by dendritic cells: tolerance and tryptophan catabolism. Nat Rev Immunol 4:762-774

15. Fallarino F, Grohmann U, Vacca C, Bianchi R, Orabona C, Spreca A, Fioretti MC, Puccetti P (2002) T cell apoptosis by tryptophan catabolism. Cell Death Differ 9:1069-1077

16. Grohmann U, Fallarino F, Puccetti P (2003) Tolerance, DCs and tryptophan: much ado about IDO. Trends Immunol 24:242-248

17. Fallarino F, Grohmann U, You S, McGrath BC, Cavener DR, Vacca C, Orabona C, Bianchi R, Belladonna ML, Volpi C, Santamaria P, Fioretti MC, Puccetti P (2006) The combined effects of tryptophan starvation and tryptophan catabolites down-regulate $\mathrm{T}$ cell receptor zeta-chain and induce a regulatory phenotype in naïve $\mathrm{T}$ cells. J Immunol 176:6752-6761 
18. Oderup C, Cederbom L, Makowska A, Cilio CM, Ivars F (2006) Cytotoxic T lymphocyte antigen-4-dependent down-modulation of costimulatory molecules on dendritic cells in CD4 + CD25+ regulatory T-cell-mediated suppression. Immunology 118:240-249

19. Qureshi OS, Zheng Y, Nakamura K, Attridge K, Manzotti C, Schmidt EM, Baker J, Jeffery LE, Kaur S, Briggs Z, Hou TZ, Futter CE, Anderson G, Walker LS, Sansom DM (2011) Transendocytosis of CD80 and CD86: a molecular basis for the cell-extrinsic function of CTLA-4. Science 332:600-603

20. Linsley PS, Nadler SG (2009) The clinical utility of inhibiting CD28-mediated costimulation. Immunol Rev 229:307-321

21. Su VC, Harrison J, Rogers C, Ensom MH (2012) Belatacept: a new biologic and its role in kidney transplantation. Ann Pharmacother 46:57-67

22. Waterhouse P, Penninger JM, Timms E, Wakeham A, Shahinian A, Lee KP, Thompson CB, Griesser H, Mak TW (1995) Lymphoproliferative disorders with early lethality in mice deficient in Ctla-4. Science 270:985-988

23. Tivol EA, Borriello F, Schweitzer AN, Lynch WP, Bluestone JA, Sharpe AH (1995) Loss of CTLA-4 leads to massive lymphoproliferation and fatal multiorgan tissue destruction, revealing a critical negative regulatory role of CTLA-4. Immunity 3:541-547

24. Leach DR, Krummel MF, Allison JP (1996) Enhancement of antitumour immunity by CTLA-4 blockade. Science 271:1734-1736

25. Kwon ED, Hurwitz AA, Foster BA, Madias C, Feldhaus AL, Greenberg NM, Burg MB, Allison JP (1997) Manipulation of T cell costimulatory and inhibitory signals for immunotherapy of prostate cancer. Proc Natl Acad Sci USA 94:8099-8103

26. Yang YF, Zou JP, Mu J, Wijesuriya R, Ono S, Walunas T, Bluestone J, Fujiwara H, Hamaoka T (1997) Enhanced induction of antitumour T-cell responses by cytotoxic T lymphocyteassociated molecule-4 blockade: the effect is manifested only at the restricted tumour-bearing stages. Cancer Res 57:4036-4041

27. Korman AJ, Peggs KS, Allison JP (2006) Checkpoint blockade in cancer immunotherapy. Adv Immunol 90:297-339

28. van Elsas A, Sutmuller RP, Hurwitz AA, Ziskin J, Villasenor J, Medema JP, Overwijk WW, Restifo NP, Melief CJ, Offringa R, Allison JP (2001) Elucidating the autoimmune and antitumour effector mechanisms of a treatment based on cytotoxic T lymphocyte antigen-4 blockade in combination with a B16 melanoma vaccine: comparison of prophylaxis and therapy. J Exp Med 194:481-489

29. Peggs KS, Quezada SA, Chambers CA, Korman AJ, Allison JP (2009) Blockade of CTLA-4 on both effector and regulatory $\mathrm{T}$ cell compartments contributes to the antitumour activity of anti-CTLA-4 antibodies. J Exp Med 206:1717-1725

30. McNeel DG, Smith HA, Eickhoff JC, Lang JM, Staab MJ, Wilding G, Liu G (2012) Phase I trial of tremelimumab in combination with short-term androgen deprivation in patients with PSA-recurrent prostate cancer. Cancer Immunol Immunother 61:1137-1147

31. Ribas A, Hauschild A, Kefford R, Punt CJ, Haanen JB, Marmol M, Garbe C, GomezNavarro J, Pavlov D, Marshall M (2008) Phase III, open-label, randomized, comparative study of tremelimumab (CP-675,206) and chemotherapy (temozolomide [TMZ] or dacarbazine [DTIC]) in patients with advanced melanoma. J Clin Oncol 26(20s), LBA9011

32. Tarhini AA, Cherian J, Moschos SJ, Tawbi HA, Shuai Y, Gooding WE, Sander C, Kirkwood JM (2012) Safety and efficacy of combination immunotherapy with interferon alfa-2b and tremelimumab in patients with stage IV melanoma. J Clin Oncol 30:322-328

33. Keler T, Halk E, Vitale L, O'Neill T, Blanset D, Lee S, Srinivasan M, Graziano RF, Davis T, Lonberg N, Korman A (2003) Activity and safety of CTLA-4 blockade combined with vaccines in cynomolgus macaques. J Immunol 171:6251-6259

34. Wolchok JD, Neyns B, Linette G, Negrier S, Lutzky J, Thomas L, Waterfield W, Schadendorf D, Smylie M, Guthrie T Jr, Grob JJ, Chesney J, Chin K, Chen K, Hoos A, O’Day SJ, Lebbé C (2010) Ipilimumab monotherapy in patients with pretreated advanced 
melanoma: a randomised, double-blind, multicentre, phase 2, dose-ranging study. Lancet Oncol 11:155-164

35. Weber JS, O'Day S, Urba W, Powderly J, Nichol G, Yellin M, Snively J, Hersh E (2008) Phase I/II study of ipilimumab for patients with metastatic melanoma. J Clin Oncol 26:5950-5956

36. Product Information (2011) Yervoy (ipilimumab). Bristol-Myers Squibb, Princeton, NJ

37. Phan GQ, Yang JC, Sherry RM, Hwu P, Topalian SL, Schwartzentruber DJ, Restifo NP, Haworth LR, Seipp CA, Freezer LJ, Morton KE, Mavroukakis SA, Duray PH, Steinberg SM, Allison JP, Davis TA, Rosenberg SA (2003) Cancer regression and autoimmunity induced by cytotoxic $\mathrm{T}$ lymphocyte-associated antigen 4 blockade in patients with metastatic melanoma. Proc Natl Acad Sci USA 100:8372-8377

38. Bafaloukos D, Gogas H (2004) The treatment of brain metastases in melanoma patients. Cancer Treat Rev 30:515-520

39. Middleton MR, Grob JJ, Aaronson N, Fierlbeck G, Tilgen W, Seiter S, Gore M, Aamdal S, Cebon J, Coates A, Dreno B, Henz M, Schadendorf D, Kapp A, Weiss J, Fraass U, Statkevich P, Muller M, Thatcher N (2000) Randomized phase III study of temozolomide versus dacarbazine in the treatment of patients with advanced metastatic malignant melanoma. J Clin Oncol 18:158-166

40. Avril MF, Aamdal S, Grob JJ, Hauschild A, Mohr P, Bonerandi JJ, Weichenthal M, Neuber K, Bieber T, Gilde K, Guillem Porta V, Fra J, Bonneterre J, Saïag P, Kamanabrou D, Pehamberger H, Sufliarsky J, Gonzalez Larriba JL, Scherrer A, Menu Y (2004) Fotemustine compared with dacarbazine in patients with disseminated malignant melanoma: a phase III study. J Clin Oncol 22:1118-1125

41. Tatar Z, Thivat E, Planchat E, Gimbergues P, Gadea E, Abrial C, Durando X (2013) Temozolomide and unusual indications: review of literature. Cancer Treat Rev 39(2): $125-135$

42. Chiarion-Sileni V, Guida M, Ridolfi L, Romanini A, Del Bianco P, Pigozzo J, Brugnara S, Colucci G, Ridolfi R, De Salvo GL (2011) Central nervous system failure in melanoma patients: results of a randomised, multicentre phase 3 study of temozolomide- and dacarbazine-based regimens. Br J Cancer 104:1816-1821

43. Tentori L, Graziani G (2009) Recent approaches to improve the antitumour efficacy of temozolomide. Curr Med Chem 16:245-257

44. Atkins MB, Lotze MT, Dutcher JP, Fisher RI, Weiss G, Margolin K, Abrams J, Sznol M, Parkinson D, Hawkins M, Paradise C, Kunkel L, Rosenberg SA (1999) High-dose recombinant interleukin 2 therapy for patients with metastatic melanoma: analysis of 270 patients treated between 1985 and 1993. J Clin Oncol 17:2105-2116

45. Korn EL, Liu PY, Lee SJ, Chapman JA, Niedzwiecki D, Suman VJ, Moon J, Sondak VK, Atkins MB, Eisenhauer EA, Parulekar W, Markovic SN, Saxman S, Kirkwood JM (2008) Meta-analysis of phase II cooperative group trials in metastatic stage IV melanoma to determine progression-free and overall survival benchmarks for future phase II trials. J Clin Oncol 26:527-534

46. Chapman PB, Hauschild A, Robert C, Haanen JB, Ascierto P, Larkin J, Dummer R, Garbe C, Testori A, Maio M, Hogg D, Lorigan P, Lebbe C, Jouary T, Schadendorf D, Ribas A, O'Day SJ, Sosman JA, Kirkwood JM, Eggermont AM, Dreno B, Nolop K, Li J, Nelson B, Hou J, Lee RJ, Flaherty KT, McArthur AG, BRIM-3 Study Group (2011) Improved survival with vemurafenib in melanoma with BRAF V600E mutation. N Engl J Med 364:2507-2516

47. Sosman JA, Kim KB, Schuchter L, Gonzalez R, Pavlick AC, Weber JS, McArthur GA, Hutson TE, Moschos SJ, Flaherty KT, Hersey P, Kefford R, Lawrence D, Puzanov I, Lewis KD, Amaravadi RK, Chmielowski B, Lawrence HJ, Shyr Y, Ye F, Li J, Nolop KB, Lee RJ, Joe AK, Ribas A (2012) Survival in BRAF V600-mutant advanced melanoma treated with vemurafenib. N Engl J Med 366:707-714

48. Hauschild A, Grob JJ, Demidov LV, Jouary T, Gutzmer R, Millward M, Rutkowski P, Blank CU, Miller WH Jr, Kaempgen E, Martín-Algarra S, Karaszewska B, Mauch C, Chiarion-Sileni V, 
Martin AM, Swann S, Haney P, Mirakhur B, Guckert ME, Goodman V, Chapman PB (2012) Dabrafenib in BRAF-mutated metastatic melanoma: a multicentre, open-label, phase 3 randomised controlled trial. Lancet 380(9839):358-365

49. Fedorenko IV, Paraiso KH, Smalley KS (2011) Acquired and intrinsic BRAF inhibitor resistance in BRAF V600E mutant melanoma. Biochem Pharmacol 82:201-209

50. Su F, Viros A, Milagre C, Trunzer K, Bollag G, Spleiss O, Reis-Filho JS, Kong X, Koya RC, Flaherty KT, Chapman PB, Kim MJ, Hayward R, Martin M, Yang H, Wang Q, Hilton H, Hang JS, Noe J, Lambros M, Geyer F, Dhomen N, Niculescu-Duvaz I, Zambon A, NiculescuDuvaz D, Preece N, Robert L, Otte NJ, Mok S, Kee D, Ma Y, Zhang C, Habets G, Burton EA, Wong B, Nguyen H, Kockx M, Andries L, Lestini B, Nolop KB, Lee RJ, Joe AK, Troy JL, Gonzalez R, Hutson TE, Puzanov I, Chmielowski B, Springer CJ, McArthur GA, Sosman JA, Lo RS, Ribas A, Marais R (2012) RAS mutations in cutaneous squamous-cell carcinomas in patients treated with BRAF inhibitors. N Engl J Med 366:207-215

51. Hodi FS, O'Day SJ, McDermott DF, Weber RW, Sosman JA, Haanen JB, Gonzalez R, Robert C, Schadendorf D, Hassel JC, Akerley W, van den Eertwegh AJ, Lutzky J, Lorigan P, Vaubel JM, Linette GP, Hogg D, Ottensmeier CH, Lebbé C, Peschel C, Quirt I, Clark JI, Wolchok JD, Weber JS, Tian J, Yellin MJ, Nichol GM, Hoos A, Urba WJ (2010) Improved survival with ipilimumab in patients with metastatic melanoma. N Engl J Med 363:711-723

52. Schwartzentruber DJ, Lawson DH, Richards JM, Conry RM, Miller DM, Treisman J, Gailani F, Riley L, Conlon K, Pockaj B, Kendra KL, White RL, Gonzalez R, Kuzel TM, Curti B, Leming PD, Whitman ED, Balkissoon J, Reintgen DS, Kaufman H, Marincola FM, Merino MJ, Rosenberg SA, Choyke P, Vena D, Hwu P (2011) gp100 peptide vaccine and interleukin-2 in patients with advanced melanoma. N Engl J Med 364:2119-2127

53. Wolchok JD, Weber JS, Hamid O, Lebbé C, Maio M, Schadendorf D, de Pril V, Heller K, Chen TT, Ibrahim R, Hoos A, O’Day SJ (2010) Ipilimumab efficacy and safety in patients with advanced melanoma: a retrospective analysis of HLA subtype from four trials. Cancer Immun 10:9

54. Robert C, Thomas L, Bondarenko I, O’Day S, M D JW, Garbe C, Lebbe C, Baurain JF, Testori A, Grob JJ, Davidson N, Richards J, Maio M, Hauschild A, Miller WH Jr, Gascon P, Lotem M, Harmankaya K, Ibrahim R, Francis S, Chen TT, Humphrey R, Hoos A, Wolchok JD (2011) Ipilimumab plus dacarbazine for previously untreated metastatic melanoma. $\mathrm{N}$ Engl $\mathrm{J}$ Med 364:2517-2526

55. Patel SP, Hwu W, Kim KB, Papadopoulos NE, Hwu P, Radvanyi LG, Mahoney S, Deburr TL, Liu P, Bedikian AYJ (2012) Phase II study of the frontline combination of ipilimumab and temozolomide in patients with metastatic melanoma. Clin Oncol 30(15s):8514

56. Ribas A, Hodi FS, Kurland JF, Shahabi V, Francis S, Konto C, Joe AK, Lainas I, Wolchok JD (2012) CA184-161: a phase I/II trial of vemurafenib and ipilimumab in patients with BRAF V600 mutation-positive metastatic melanoma. J Clin Oncol 30(15s):8603

57. Davies MA, Liu P, McIntyre S, Kim KB, Papadopoulos N, Hwu WJ, Hwu P, Bedikian A (2011) Prognostic factors for survival in melanoma patients with brain metastases. Cancer 117:1687-1696

58. Hodi FS, Oble DA, Drappatz J, Velazquez EF, Ramaiya N, Ramakrishna N, Day AL, Kruse A, Mac Rae S, Hoos A, Mihm M (2008) CTLA-4 blockade with ipilimumab induces significant clinical benefit in a female with melanoma metastases to the CNS. Nat Clin Pract Oncol 5:557-561

59. Schartz NE, Farges C, Madelaine I, Bruzzoni H, Calvo F, Hoos A, Lebbé C (2010) Complete regression of a previously untreated melanoma brain metastasis with ipilimumab. Melanoma Res 20:247-250

60. Margolin K, Ernstoff MS, Hamid O, Lawrence D, McDermott D, Puzanov I, Wolchok JD, Clark JI, Sznol M, Logan TF, Richards J, Michener T, Balogh A, Heller KN, Hodi FS (2012) Ipilimumab in patients with melanoma and brain metastases: an open-label, phase 2 trial. Lancet Oncol 13:459-465 
61. Margolin KA, Di Giacomo AM, Maio M (2010) Brain metastasis in melanoma: clinical activity of CTLA-4 antibody therapy. Semin Oncol 37:468-472

62. Di Giacomo AM, Ascierto PA, Pilla L, Ridolfi R, Santinami M, Testori A, Queirolo P, Simeone E, Guidoboni M, Del Vecchio M, Ferrucci PF, Marasco A, Fonsatti E, Annesi D, Giannarelli D, Parmiani G, Maio M (2012) Phase II multicenter trial of ipilimumab combined with fotemustine in patients with metastatic melanoma: the Italian Network for Tumour Biotherapy (NIBIT)-M1 trial. J Clin Oncol 30(15s):8513

63. Maio M, Testori A, Ascierto PA, Ridolfi R, Santinami M, Pilla L, Queirolo P, Grosso M, Simeone E, Vittoria S, Nicoletti L, Rivoltini L, Ferrucci PF, Parmiani G, Di Giacomo AM (2012) The NIBIT-M1 trial: activity of ipilimumab plus fotemustine in patients with melanoma and brain metastases. J Clin Oncol 30(15s):8529

64. Postow MA, Callahan MK, Barker CA, Yamada Y, Yuan J, Kitano S, Mu Z, Rasalan T, Adamow M, Ritter E, Sedrak C, Jungbluth AA, Chua R, Yang AS, Roman RA, Rosner S, Benson B, Allison JP, Lesokhin AM, Gnjatic S, Wolchok JD (2012) Immunologic correlates of the abscopal effect in a patient with melanoma. N Engl J Med 366:925-931

65. Stamell EF, Wolchok JD, Gnjatic S, Lee NY, Brownell I (2013) The abscopal effect associated with a systemic anti-melanoma immune response. Int J Radiat Oncol Biol Phys 85(2):293-295

66. Danielli R, Ridolfi R, Chiarion-Sileni V, Queirolo P, Testori A, Plummer R, Boitano M, Calabrò L, Rossi CD, Giacomo AM, Ferrucci PF, Ridolfi L, Altomonte M, Miracco C, Balestrazzi A, Maio M (2012) Ipilimumab in pretreated patients with metastatic uveal melanoma: safety and clinical efficacy. Cancer Immunol Immunother 61:41-48

67. Khan SA, Callahan M, Postow MA, Chapman PB, Schwartz GK, Dickson MA, D'Angelo SP, Luke JJ, Bluth MJ, Roman RA, Montefusco M, Barker CA, Abramson DH, Wolchok JD, Carvajal RD (2012) Ipilimumab in the treatment of uveal melanoma: the Memorial SloanKettering Cancer Center experience. J Clin Oncol 30(15s):8513

68. Tarhini AA, Edington H, Butterfield LH, Tawbi H, Moschos SJ, Shuai Y, Lin Y, Horak M, Sarkisian S, Shipe-Spotloe J, Milburn C, Sander C, Johnson TJ, Kirkwood JM (2012) Neoadjuvant ipilimumab in locally/regionally advanced melanoma: clinical outcome and immune monitoring. J Clin Oncol 30(15s):8514

69. Van Nuffel AM, Benteyn D, Wilgenhof S, Corthals J, Heirman C, Neyns B, Thielemans K, Bonehill A (2012) Intravenous and intradermal TriMix-dendritic cell therapy results in a broad T-cell response and durable tumour response in a chemorefractory stage IV-M1c melanoma patient. Cancer Immunol Immunother 61:1033-1043

70. Higano CS, Crawford ED (2011) New and emerging agents for the treatment of castrationresistant prostate cancer. Urol Oncol 29:S1-S8

71. Small EJ, Tchekmedyian NS, Rini BI, Fong L, Lowy I, Allison JP (2007) A pilot trial of CTLA-4 blockade with human anti-CTLA-4 in patients with hormone-refractory prostate cancer. Clin Cancer Res 13:1810-1815

72. Fong L, Kwek SS, O’Brien S, Kavanagh B, McNeel DG, Weinberg V, Lin AM, Rosenberg J, Ryan CJ, Rini BI, Small EJ (2009) Potentiating endogenous antitumour immunity to prostate cancer through combination immunotherapy with CTLA4 blockade and GM-CSF. Cancer Res 69:609-615

73. Slovin SF, Beer TM, Higano CS, Tejwani S, Hamid O, Picus J, Harzstark A, Scher HI, Lan Z, Lowy I (2009) Prostate Cancer Clinical Trials Consortium. Initial phase II experience of ipilimumab (IPI) alone and in combination with radiotherapy (XRT) in patients with metastatic castration-resistant prostate cancer (mCRPC). J Clin Oncol 27(15s):5138

74. Drake CG, Scher HI, Bossi A, van den Eertwegh AJM, McHenry B, Fitzmaurice TF, Cuillerot JM, Chin KM, Gagnier P, Fizazi K, Gerritsen WR (2012) CA184-043: a randomized, double-blind, phase III trial comparing ipilimumab versus placebo following a single dose of radiotherapy (RT) in patients (pts) with castration-resistant prostate cancer (CRPC) who have received prior treatment with docetaxel (D). J Clin Oncol 30(15s): TPS4689 
75. Beer TM, Logothetis C, Sharma P, Bossi A, McHerry B, Fairchild JP, Gagnier P, Chin KM, Cuillerot JM, Fizazi K, Gerritsen WR (2012) CA184-095: a randomized, double-blind, phase III trial to compare the efficacy of ipilimumab versus placebo in asymptomatic or minimally symptomatic patients (pts) with metastatic chemotherapy-naïve castration-resistant prostate cancer (CRPC). J Clin Oncol 30(15s):TPS4691

76. van den Eertwegh AJ, Versluis J, van den Berg HP, Santegoets SJ, van Moorselaar RJ, van der Sluis TM, Gall HE, Harding TC, Jooss K, Lowy I, Pinedo HM, Scheper RJ, Stam AG, von Blomberg BM, de Gruijl TD, Hege K, Sacks N, Gerritsen WR (2012) Combined immunotherapy with granulocyte-macrophage colony-stimulating factor-transduced allogeneic prostate cancer cells and ipilimumab in patients with metastatic castration-resistant prostate cancer: a phase 1 dose-escalation trial. Lancet Oncol 13:509-517

77. Madan RA, Mohebtash M, Arlen PM, Vergati M, Rauckhorst M, Steinberg SM, Tsang KY, Poole DJ, Parnes HL, Wright JJ, Dahut WL, Schlom J, Gulley JL (2012) Ipilimumab and a poxviral vaccine targeting prostate-specific antigen in metastatic castration-resistant prostate cancer: a phase 1 dose-escalation trial. Lancet Oncol 13:501-508

78. Lynch TJ, Bondarenko I, Luft A, Serwatowski P, Barlesi F, Chacko R, Sebastian M, Neal J, Lu H, Cuillerot JM, Reck M (2012) Ipilimumab in combination with paclitaxel and carboplatin as first-line treatment in stage IIIB/IV non-small-cell lung cancer: results from a randomized, double-blind, multicenter phase II study. J Clin Oncol 30:2046-2054

79. Reck M, Lu H, Gribkoff G, Maier S, McGovern R, Cuillerot JM, Lynch TJ (2012) CA184104: randomized, multicenter, double-blind, phase III trial comparing the efficacy of ipilimumab (Ipi) with paclitaxel/carboplatin (PC) versus placebo with PC in patients (pts) with stage IV/recurrent non-small cell lung cancer (NSCLC) of squamous histology. J Clin Oncol 30(15s):TPS4691

80. Spigel DR, Zielinski C, Maier S, de Pril V, Fairchild JP, Cuillerot JM, Reck M (2012) CA184-156: a randomized, multicenter, double-blind, phase III trial comparing the efficacy of ipilimumab (Ipi) plus etoposide/platinum (EP) versus EP in subjects with newly diagnosed extensive-stage disease small cell lung cancer (ED-SCLC). J Clin Oncol 30(15s):TPS7113

81. Yang JC, Hughes M, Kammula U, Royal R, Sherry RM, Topalian SL, Suri KB, Levy C, Allen T, Mavroukakis S, Lowy I, White DE, Rosenberg SA (2007) Ipilimumab (anti-CTLA4 antibody) causes regression of metastatic renal cell cancer associated with enteritis and hypophysitis. J Immunother 30:825-830

82. Gartrell BA, Hahn NM, Hutson TE, Sonpavde G, Hauke RJ, Starodub A, Small AC, Tsao CK, Galsky MD (2012) Phase II trial of gemcitabine and cisplatin plus ipilimumab as first-line treatment for metastatic urothelial carcinoma. J Clin Oncol 30(15s):TPS4676

83. Carthon BC, Wolchok JD, Yuan J, Kamat A, Ng Tang DS, Sun J, Ku G, Troncoso P, Logothetis CJ, Allison JP, Sharma P (2010) Preoperative CTLA-4 blockade: tolerability and immune monitoring in the setting of a presurgical clinical trial. Clin Cancer Res 16: 2861-2871

84. Wolchok JD, Hoos A, O’Day S, Weber JS, Hamid O, Lebbé C, Maio M, Binder M, Bohnsack O, Nichol G, Humphrey R, Hodi FS (2009) Guidelines for the evaluation of immune therapy activity in solid tumours: immune-related response criteria. Clin Cancer Res 15: 7412-7420

85. Ribas A, Chmielowski B, Glaspy JA (2009) Do we need a different set of response assessment criteria for tumour immunotherapy? Clin Cancer Res 15:7116-7118

86. Ibrahim RA, Berman DM, DePril V, Humphrey RW, Chen T, Messina M, Chin KM, Liu HY, Bielefield M, Hoos A (2011) Ipilimumab safety profile: Summary of findings from completed trials in advanced melanoma. J Clin Oncol 29(18s):8583

87. Revicki DA, van den Eertwegh AJ, Lorigan P, Lebbe C, Linette G, Ottensmeier CH, Safikhani S, Messina M, Hoos A, Wagner S, Kotapati S (2012) Health related quality of life outcomes for unresectable stage III or IV melanoma patients receiving ipilimumab treatment. Health Qual Life Outcomes 10:66 
88. Thomas L, Wolchok JD, Garbe C, Lebbe C, Bondarenko I, Rodrigues K, Konto C, Chin KM, Francis S, Robert C (2012) Safety of ipilimumab in patients (pts) with untreated, advanced melanoma alive beyond 2 years: results from a phase III study. J Clin Oncol 30(15s):8512

89. Kähler KC, Hauschild A (2011) Treatment and side effect management of CTLA-4 antibody therapy in metastatic melanoma. J Dtsch Dermatol Ges 9:277-286

90. Thumar JR, Kluger HM (2010) Ipilimumab: a promising immunotherapy for melanoma. Oncology 24:1280-1288

91. Harmankaya K, Erasim C, Koelblinger C, Ibrahim R, Hoos A, Pehamberger H, Binder M (2011) Continuous systemic corticosteroids do not affect the ongoing regression of metastatic melanoma for more than two years following ipilimumab therapy. Med Oncol 28:1140-1144

92. Graziani G, Tentori L, Navarra P (2012) Ipilimumab: a novel immunostimulatory monoclonal antibody for the treatment of cancer. Pharmacol Res 65:9-22

93. Attia P, Phan GQ, Maker AV, Robinson MR, Quezado MM, Yang JC, Sherry RM, Topalian SL, Kammula US, Royal RE, Restifo NP, Haworth LR, Levy C, Mavroukakis SA, Nichol G, Yellin MJ, Rosenberg SA (2005) Autoimmunity correlates with tumour regression in patients with metastatic melanoma treated with anti-cytotoxic T-lymphocyte antigen-4. J Clin Oncol 23:6043-6053

94. Lutzky J, Wolchok J, Hamid O, Lebbe C, Pehamberger H, Linette G, de Pril V, Ibrahim R, Hoos A, O'Day S (2009) Association between immune-related adverse events (irAEs) and disease control or overall survival in patients (pts) with advanced melanoma treated with $10 \mathrm{mg} / \mathrm{kg}$ ipilimumab in three phase II clinical trials. J Clin Oncol 27(15s):9034

95. Hodi FS, Mihm MC, Soiffer RJ, Haluska FG, Butler M, Seiden MV, Davis T, Henry-Spires R, MacRae S, Willman A, Padera R, Jaklitsch MT, Shankar S, Chen TC, Korman A, Allison JP, Dranoff G (2003) Biologic activity of cytotoxic T lymphocyte-associated antigen 4 antibody blockade in previously vaccinated metastatic melanoma and ovarian carcinoma patients. Proc Natl Acad Sci USA 100:4712-4717

96. Beck KE, Blansfield JA, Tran KQ, Feldman AL, Hughes MS, Royal RE, Kammula US, Topalian SL, Sherry RM, Kleiner D, Quezado M, Lowy I, Yellin M, Rosenberg SA, Yang JC (2006) Enterocolitis in patients with cancer after antibody blockade of cytotoxic T-lymphocyte-associated antigen 4. J Clin Oncol 24:2283-2289

97. Weber JS, Kähler KC, Hauschild A (2012) Management of immune-related adverse events and kinetics of response with ipilimumab. J Clin Oncol 30:2691-2697

98. Weber J, Thompson JA, Hamid O, Minor D, Amin A, Ron I, Ridolfi R, Assi H, Maraveyas A, Berman D, Siegel J, O’Day SJ (2009) A randomized, double-blind, placebo-controlled, phase II study comparing the tolerability and efficacy of ipilimumab administered with or without prophylactic budesonide in patients with unresectable stage III or IV melanoma. Clin Cancer Res 15:5591-5598

99. Kleiner DE, Berman D (2012) Pathologic changes in ipilimumab-related hepatitis in patients with metastatic melanoma. Dig Dis Sci 57:2233-2240

100. Juszczak A, Gupta A, Karavitaki N, Middleton MR, Grossman AB (2012) Mechanisms in endocrinology: Ipilimumab: a novel immunomodulating therapy causing autoimmune hypophysitis: a case report and review. Eur J Endocrinol 167:1-5

101. Berthod G, Lazor R, Letovanec I, Romano E, Noirez L, Mazza Stalder J, Speiser DE, Peters S, Michielin O (2012) Pulmonary sarcoid-like granulomatosis induced by ipilimumab. J Clin Oncol 30:e156-e159

102. Vogel WV, Guislain A, Kvistborg P, Schumacher TN, Haanen JB, Blank CU (2012) Ipilimumab-induced sarcoidosis in a patient with metastatic melanoma undergoing complete remission. J Clin Oncol 30:e7-e10

103. Eckert A, Schoeffler A, Dalle S, Phan A, Kiakouama L, Thomas L (2009) Anti-CTLA4 monoclonal antibody induced sarcoidosis in a metastatic melanoma patient. Dermatology 218:69-70

104. Delyon J, Mateus C, Lambert T (2011) Hemophilia A induced by ipilimumab. N Engl J Med 365:1747-1748 